\title{
Development of a simulation model for analyzing vibrations of a double cabin fire truck and their effects on firefighters
}

\author{
Flóra Hajdu ${ }^{1}$, Rajmund Kuti ${ }^{1}$ \\ Department of Mechatronics and Machine Design, Faculty of Mechanical Engineering, Informatics and Electrical \\ Engineering, Széchenyi István University, Györ, Hungary ${ }^{1}$
}

\begin{abstract}
Various vibrations occur in vehicles, which are generated by the vehicle's equipment or by the road itself. Several studies have been carried out on the investigation of vibrations in passenger cars or different purpose trucks, but there is little literature available on the analysis of special superstructure vehicles such as fire trucks. During our research therefore a simulation model for analyzing the vibrations of a double-cabin special fire truck was created. The main purpose of our research is investigating their effects on people traveling in fire-fighting vehicles. In this paper the developed model and the computer simulation using it is presented. With our results we want to draw the attention to the importance of the topic and to help the safe operation of fire-fighting vehicles.
\end{abstract}

Keywords: Double cabin fire truck, firefighter crew, vibrations, numerical simulation

\section{INTRODUCTION}

Various vibrations occur during operation of machines [1] and vehicles [2], which have an impact on the equipment itself and on the operator [3] or the person driving or traveling in it [4]. Scientific research on the resulting vibrations and their effects is an important task, since harmful vibrations can cause serious health problems [5]-[6]. The drivers of fire trucks and the on-board firefighter crew are also subject to increased load. Driving at the highest possible speed to the locations of fires or accidents is a heavy burden on both the vehicle and the crew [7]. Most of the literature deals with the vibrations on people driving or traveling in passenger cars [8]-[10] or trucks [11]-[13]. The effects of vibrations on people traveling on special vehicles including fire trucks them has not yet been investigated. In this paper the mathematical modeling and numerical simulation of a MB RB TLF 2000 double-cabin fire truck is presented. The model was developed in order to examine the vibrations on the firefighter crew.

\section{TECHNICAL PARAMETERS OF THE TESTED VEHICLE}

The vehicle chosen for our research is a mid-range fire truck with an Austrian-built Rosenbauer superstructure built on a German Mercedes-Benz 1124 chassis. The vehicle has a ladder frame with rigid front and rear axles. The vehicle is all-wheel drive with lockable tranfer gear. Both axles are equipped with leaf springs and an auxiliary leaf spring for permanent load is installed at the rear axle. Hydraulic shock absorbers on both sides provide the proper road holding. The vehicle is powered by a $117 \mathrm{~kW}$ Mercedes-Benz OM366LA-Euro II. refueling four-stroke diesel engine that drives the RB-NH30 type $2+2$ step fire pump through a separate drive. The vehicle was equipped with a special fire truck superstructure, including the 4-person crew compartment. The special fire fighting equipment, which contains the 2000-liter water tank and the 200 -liter foam tank, as well as the 2400 liter / min water/foam pump and the storage compartments for fire-fighting equipment and hoses are also built in the superstructure. The superstructure is fixed with a separate subframe to the vehicle chassis. The 125-liter fuel tank is fixed on the right, the battery compartment on the left to the superstructure. The driver's cabin is 2-person, tiltable, detached from the superstructure and secured to the main chassis with special rubber mount. The rear of the cabin and the front part of the crew compartment were cut to provide a common space. There is a special rubber seal between the cabin and the crew compartment, which ensures the movement of the parts, while sealing the surfaces. The vehicle is equipped with a $6+1$-speed synchronous transmission unit, with a top speed of $110 \mathrm{~km} / \mathrm{h}$ according to manufacturer's catalogue.

The structure of the vehicle is showed in Fig 1 and in Table I. 


\section{International Advanced Research Journal in Science, Engineering and Technology}

Vol. 6, Issue 5, May 2019
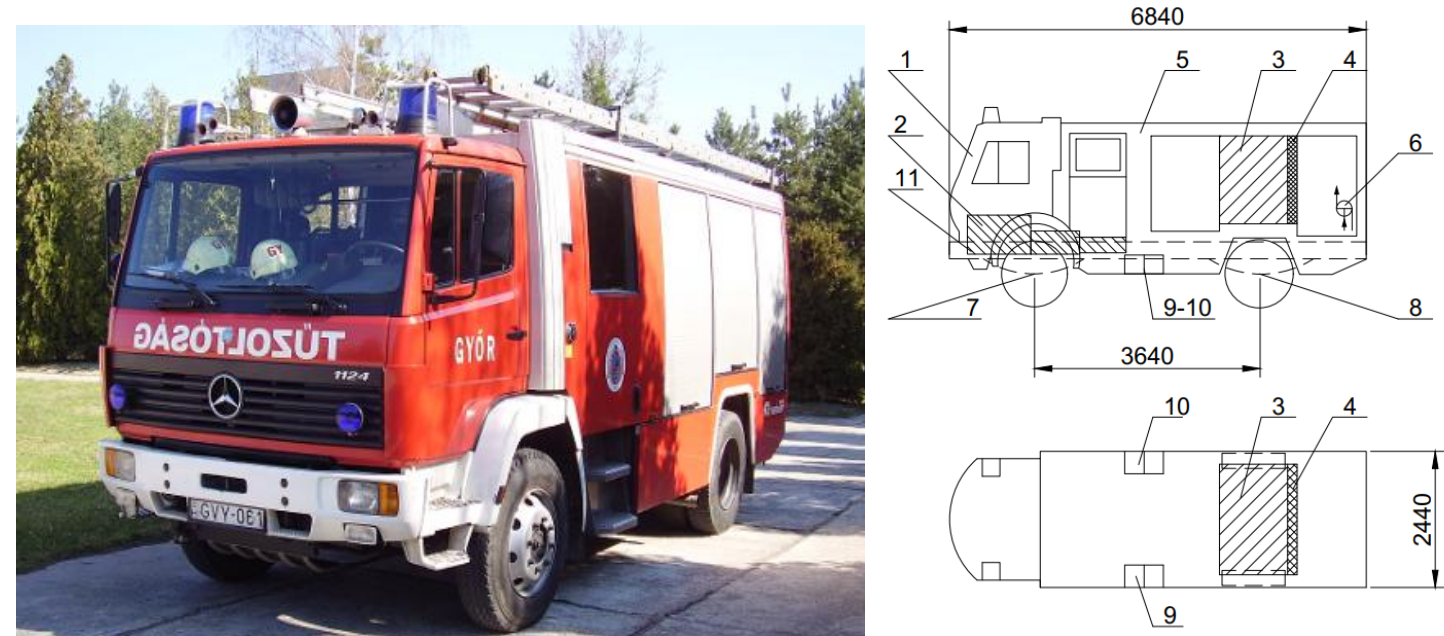

Fig 1. MB RB TLF 2000 fire truck (the length and width dimensions of the vehicle are in mm)

TABLE I. MASS PARAMETERS (BASED OR MANUFACTURERS CATALOGUE)

\begin{tabular}{|c|c|c|}
\hline Title number & Name & Mass [kg] \\
\hline 1 & Cabin & 450 \\
\hline 2 & Engine + transmission & 2400 \\
\hline 3 & Water tank (2000 l) & 2200 \\
\hline 4 & Foam tank 200 1) & 225 \\
\hline 5 & $\begin{array}{c}\text { Superstructure (crew compartment } \\
+ \text { equipment) }\end{array}$ & 4130 \\
\hline 6 & Pump & 240 \\
\hline 7 & Front axle & 450 \\
\hline 8 & Rear axle & 670 \\
\hline 9 & Battery & 100 \\
\hline 10 & Fuel tank & 2500 \\
\hline 11 & Chassis & $\Sigma 13500$ \\
\hline
\end{tabular}

\section{III.MODEL OF THE DOUBLE CABIN FIRE TRUCK SUSPENSION}

The model was based on the half-vehicle model developed in [14]. It was expanded with additional elements, like cabin and superstructure separated from the chassis. The driver seat was modelled as an additional mass-spring-damper system [15]. The model can be seen in Fig 2.

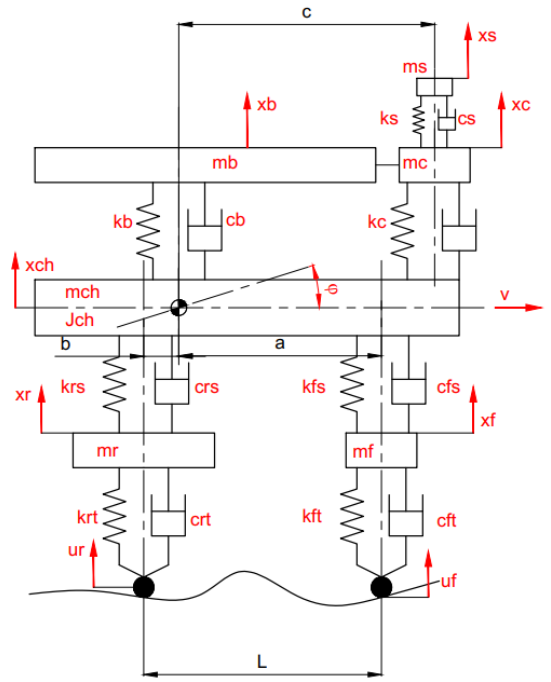

Fig. 2. Dynamic model of the vehicle 


\section{International Advanced Research Journal in Science, Engineering and Technology}

Vol. 6, Issue 5, May 2019

The equations of motion describing the system's dynamics can be obtained with free-body diagrams [16][16].

The equations describing the suspension's behavior

$$
\begin{aligned}
& m_{s} \ddot{x_{s}}=F_{k s}+F_{c s} \\
& m_{c} \ddot{x}_{c}=-F_{k s}-F_{c s}+F_{k c}+F_{c c} \\
& m_{c} \ddot{x}_{c}=-F_{k s}-F_{c s}+F_{k c}+F_{c c} \\
& m_{b} \ddot{x}_{b}=F_{k b}+F_{c b} \\
& m \ddot{x_{c h}}=-F_{k c}-F_{c c}-F_{k b}-F_{c b}+F_{k s r}+F_{c s r}+F_{k s l}+F_{c s l} \\
& J \ddot{\varphi}=-\left(F_{k c}+F_{c c}\right) c+\left(F_{k s r}+F_{c s r}\right) b+\left(F_{k s l}+F_{c s l}\right) a \\
& m_{r} \ddot{x}_{r}=-F_{k s r}-F_{c s r}+F_{k t r}+F_{c t r} \\
& m_{f} \ddot{x_{f}}=-F_{k s f}-F_{c s f}+F_{k t f}+F_{c t f}
\end{aligned}
$$

The rubber mount was modeled as a simple, commonly used Kelvin-Voigt model that consists of a spring and a damper coupled in parallel [17]. The rubber mount of the cabin and the seat suspensions were modelled as a linear spring and damper. The damping effect of the tire was also modelled as a linear damper.

$$
\begin{aligned}
F_{k i} & =k_{i} \Delta u_{i j} \\
F_{c i} & =c_{i} \Delta \dot{u}_{i j}
\end{aligned}
$$

The force applied by the tire and the force applied by the suspension leaf spring are approximated by the following nonlinear equation. The tire is modelled by a similar nonlinear spring with a smaller nonlinear equation [15].

$$
F_{k i}=k_{i} \cdot \operatorname{sgn}\left(\Delta u_{i j}\right)\left|\Delta u_{i j}\right|^{n_{i}}
$$

The damping force of the shock absorbers is approximated by the following equation [15].

$$
F_{c i}=c_{i} \cdot \operatorname{sgn}\left(\Delta \dot{u_{i j}}\right)\left|\Delta \dot{u_{i j}}\right|^{n_{i}}
$$

The relative displacement are

$$
\begin{gathered}
\Delta u_{s c}=x_{s}-x_{c} \\
\Delta u_{c h b}=x_{b}-x_{c h} \\
\Delta u_{c h c}=x_{c}-x_{m}+\varphi c \\
\Delta u_{c h f s}=x_{m}-x_{f}-\varphi a \\
\Delta u_{c h r s}=x_{m}-x_{r}+\varphi b \\
\Delta u_{f s t}=x_{f}-u_{f} \\
\Delta u_{r s t}=x_{r}-u_{r}
\end{gathered}
$$

The mass parameters of the vehicle were taken from manufacturer's catalog. The parameters of spring stiffness and the damping coefficients were taken from literature [19]-[22]. The parameters used for simulation are listed in Table II.

TABLE II. PARAMETERS USED FOR SIMULATION

\begin{tabular}{|l|c|c|c|}
\hline \multicolumn{1}{|c|}{ Name } & Notation & Value & Unit \\
\hline mass of seat + firefighter & $\mathrm{m}_{\mathrm{s}}$ & 100 & $\mathrm{~kg}$ \\
\hline mass of cabin & $\mathrm{m}_{\mathrm{c}}$ & 205 & $\mathrm{~kg}$ \\
\hline mass of superstructure & $\mathrm{m}_{\mathrm{b}}$ & 3515 & $\mathrm{~kg}$ \\
\hline mass of chassis & $\mathrm{m}_{\mathrm{ch}}$ & 2567.5 & $\mathrm{~kg}$ \\
\hline mass of front suspension & $\mathrm{m}_{\mathrm{f}}$ & 225 & $\mathrm{~kg}$ \\
\hline mass of rear suspension & $\mathrm{m}_{\mathrm{r}}$ & 335 & $\mathrm{~kg}$ \\
\hline moment of inertia of vehicle body & $\mathrm{I}_{\mathrm{p}}$ & 26130 & $\mathrm{kgm}^{2}$ \\
\hline rear axle distance from centre of mass & $\mathrm{b}$ & 0.2 & $\mathrm{~m}$ \\
\hline front axle distance from centre of mass & $\mathrm{a}$ & 3.44 & $\mathrm{~m}$ \\
\hline cabin distance from centre of mass & $\mathrm{c}$ & 3.5 & $\mathrm{~m}$ \\
\hline seat spring stiffness & $\mathrm{k}_{\mathrm{s}}$ & 20000 & $\mathrm{~N} / \mathrm{m}$ \\
\hline cabin rubber mount spring stiffness & $\mathrm{k}_{\mathrm{c}}$ & 75000 & $\mathrm{~N} / \mathrm{m}$ \\
\hline superstructure rubber mount spring stiffness & $\mathrm{k}_{\mathrm{b}}$ & 75000 & $\mathrm{~N} / \mathrm{m}$ \\
\hline
\end{tabular}


International Advanced Research Journal in Science, Engineering and Technology

Vol. 6, Issue 5, May 2019

\begin{tabular}{|c|c|c|c|}
\hline rear suspension spring stiffness & $\mathrm{k}_{\mathrm{rs}}$ & 400000 & $\mathrm{~N} / \mathrm{m}$ \\
\hline front suspension spring stiffness & $\mathrm{k}_{\mathrm{fs}}$ & 300000 & $\mathrm{~N} / \mathrm{m}$ \\
\hline rear tire spring stiffness & $\mathrm{k}_{\mathrm{rt}}$ & 1800000 & $\mathrm{~N} / \mathrm{m}$ \\
\hline front tire spring stiffness & $\mathrm{k}_{\mathrm{ft}}$ & 1000000 & $\mathrm{~N} / \mathrm{m}$ \\
\hline seat damping coefficient & $\mathrm{c}_{\mathrm{S}}$ & 1000 & $\mathrm{Ns} / \mathrm{m}$ \\
\hline cabin rubber mount damping coefficient & $\mathrm{c}_{\mathrm{c}}$ & 7500 & $\mathrm{Ns} / \mathrm{m}$ \\
\hline superstructure rubber mount damping coefficient & $\mathrm{c}_{\mathrm{b}}$ & 7500 & $\mathrm{Ns} / \mathrm{m}$ \\
\hline rear suspension damping coefficient & $\mathrm{c}_{\mathrm{rs}}$ & 40000 & $\mathrm{Ns} / \mathrm{m}$ \\
\hline front suspension damping coefficient & $\mathrm{c}_{\mathrm{fs}}$ & 20000 & $\mathrm{Ns} / \mathrm{m}$ \\
\hline rear tire damping coefficient & $\mathrm{c}_{\mathrm{rt}}$ & 1000 & $\mathrm{Ns} / \mathrm{m}$ \\
\hline front tire damping coefficient & $\mathrm{c}_{\mathrm{ft}}$ & 500 & $\mathrm{Ns} / \mathrm{m}$ \\
\hline rear suspension spring nonlinear coefficient & $\mathrm{n}_{\mathrm{krs}}$ & 1.45 & \\
\hline front suspension spring nonlinear coefficient & $\mathrm{n}_{\mathrm{kfs}}$ & 1.3 & \\
\hline rear tire spring nonlinear coefficient & $\mathrm{n}_{\mathrm{krt}}$ & 1.1 & \\
\hline front tire spring nonlinear coefficient & $\mathrm{n}_{\mathrm{kft}}$ & 1.1 & \\
\hline rear suspension damping nonlinear coefficient & $\mathrm{n}_{\mathrm{crs}}$ & 2.2 & \\
\hline front suspension damping nonlinear coefficient & $\mathrm{n}_{\mathrm{cfs}}$ & 2.2 & \\
\hline
\end{tabular}

2 different road profiles were used depending on the operation conditions: a motorway with vehicle speed $110 \mathrm{~km} / \mathrm{h}$ and an urban road with vehicle speed $50 \mathrm{~km} / \mathrm{h}$. The motorway and the urban road were modeled as a sinusoidal road profile, which can be described by the following equations:

$$
\begin{gathered}
x_{f}(t)=A \cdot \sin (\omega t) \\
x_{r}(t)=A \cdot \sin \left(\omega t-T_{d} \cdot \omega\right)
\end{gathered}
$$

where $\omega$ is the rotational speed, Td is the time delay. Rotational speed depends on the velocity of the vehicle and the wavelength

$$
\omega=\frac{2 \pi v}{\lambda}
$$

The time delay between the front and rear axle is taken into account with the following equation [23]:

$$
T_{d}=\frac{L}{V}
$$

The parameters of the different roads are summarized in Table III. [24].

\section{TABLE III. PARAMETERS OF THE ROAD PROFILES}

\begin{tabular}{|l|c|c|c|}
\hline Road type & Wavelength $[\mathrm{m}]$ & Amplitude $[\mathrm{m}]$ & Vehicle speed $[\mathrm{km} / \mathrm{h}]$ \\
\hline motorway & 10 & 0.02 & 110 \\
\hline urban road & 2 & 0.02 & 50 \\
\hline
\end{tabular}

The acceleration of the crew compartment can be calculated with the following equation:

$$
\boldsymbol{a}_{\text {crew }}=\boldsymbol{a}_{s}+\frac{d}{d t}\left(\boldsymbol{\omega} x \boldsymbol{r}_{\text {crew }}\right)
$$

where $a_{\text {crew }}$ is the acceleration at the crew compartment, $a_{s}$ is the acceleration at the centre of mass, $\omega$ is the angular velocity and $r_{\text {crew }}=2.5 \mathrm{~m}$ is the distance vector.

\section{IV.SIMULATION RESULTS}

Numerical simulations were carried out with Maple. ODE45 numerical algorithm was used for calculations with step $0.01 \mathrm{~s}$ [25]. The simulation results can be seen is Fig 3. and Fig 4. In Fig 3. the phase-plane diagrams and the frequency spectrum diagrams of the driver's seat is shown. In Fig 4. the phase-plane diagrams and the frequency spectrum diagrams of the crew compartment are presented. 


\section{International Advanced Research Journal in Science, Engineering and Technology}

Vol. 6, Issue 5, May 2019
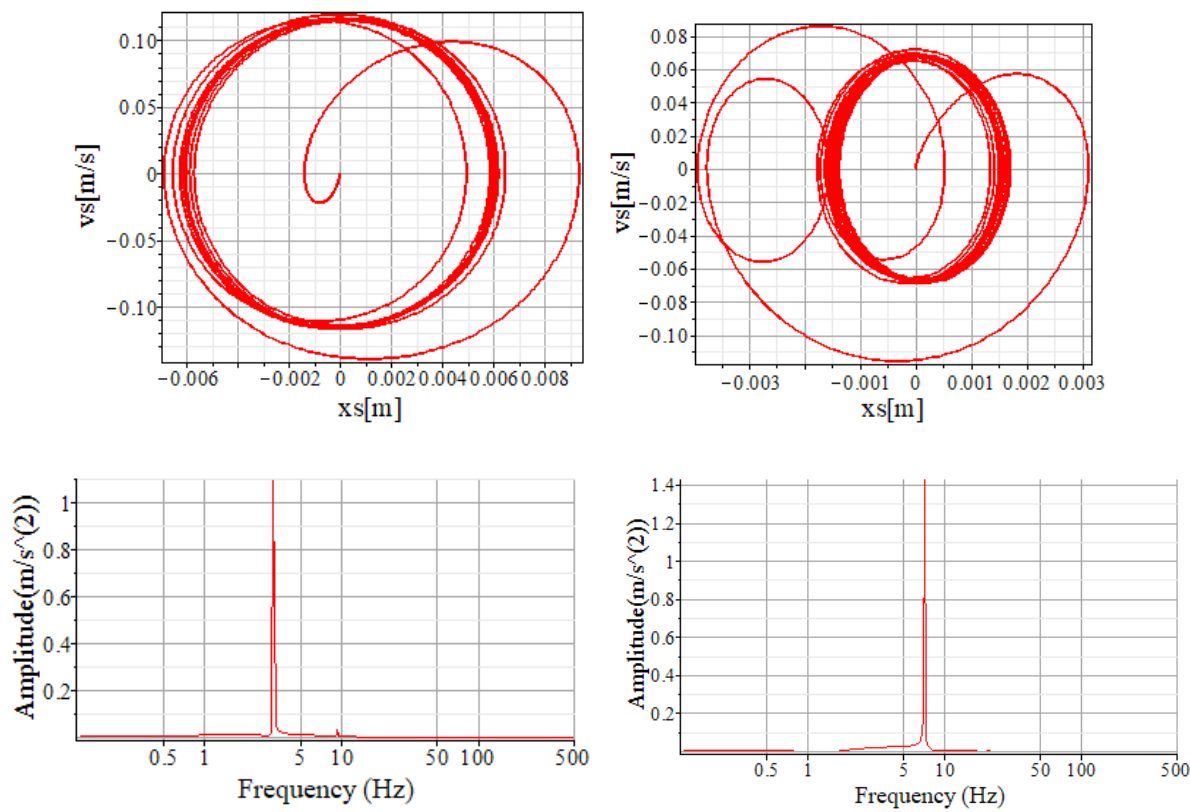

Fig. 3. Phase plane diagram (up) and frequency spectrum diagram (below) of the driver's seat (left: motorway, middle: urban road)

It can be seen int he phase plane diagrams that there is a harmonic vibration. The peak frequency is $3 \mathrm{~Hz}$ in case of motorway with 1.1 amplitude. The peak frequency is $7 \mathrm{~Hz}$ with 1.4 amplitude in case of urban roads, which exceeds the exposure limit of 8 hours [26]. As the maximum travel time to location of fires and accidents is 25-30 min in Hungary therefore it is not harmful. According to [6] the resulting vibrations are uncomfortable in both cases.
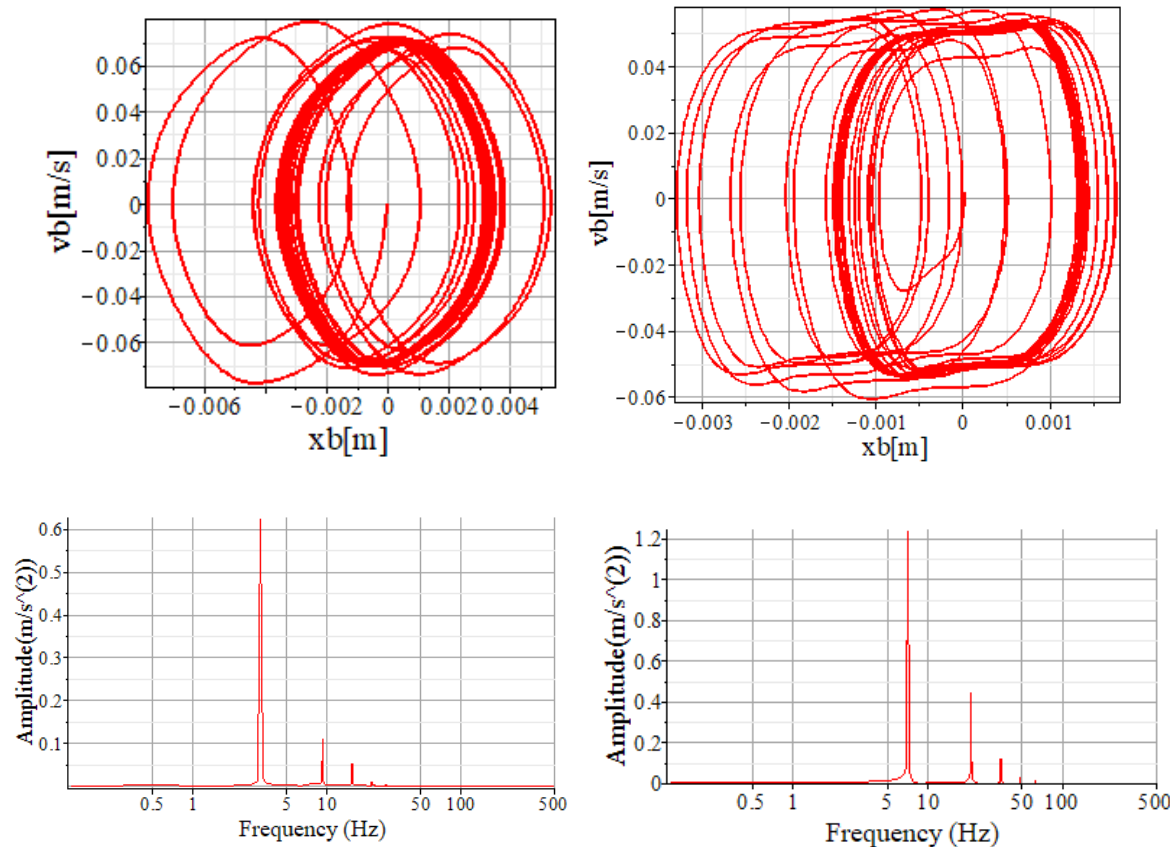

Fig. 4. Phase plane diagram (up) and frequency spectrum diagram (below) of the crew compartment (left: motorway, middle: urban road)

It can be seen in the phase plane diagrams that there is a subharmonic vibration. The peak frequency is $3 \mathrm{~Hz}$ in case of motorway with 0.6 amplitude. The peak frequency is $7 \mathrm{~Hz}$ with 1.2 amplitude in case of urban roads, which exceeds the exposure limit of 8 hours [26]. As the maximum travel time to location of fires and accidents is 25-30 min in Hungary therefore it is not harmful. According to [6] the resulting vibrations are uncomfortable in case of urban roads. 


\title{
International Advanced Research Journal in Science, Engineering and Technology
}

\author{
Vol. 6, Issue 5, May 2019
}

\section{Conclusions}

During our research a simulation model that is suitable for the examination of vibrations of persons traveling in double cabin vehicles with special superstructure was developed. The model was tested with sinusoidal road profiles of a motorway and an urban road. Based on computer simulation it can be concluded that the resulting vibrations are more harmful in case of urban roads. It was also found out that in case of normal condition roads the resulting vibrations in the examined time interval are not harmful, but are uncomfortable to people traveling in them. Next task in our research is to examine the effects of road failures on firefighters and using more precise road profiles. We have come to the conclusion that proper simulation models are essential for results that can be used in practice. We consider it important to develop appropriate models for accurate research on firefighting vehicles as they are essential for exploring the theoretical and practical phenomena and helping to identify further research directions.

\section{ACKNOWLEDGMENT}

This study was supported by the ÚNKP-18-3 New National Excellence Program of the Ministry of Human Capacities.

\section{REFERENCES}

[1]. G. Stépán, "Delay-differential equation models for machine tool chatter, Dynamics and Chaos in Manufacturing Processes", Vol. 471152935, pp. 165-192., 1998

[2]. D. Takács, G. Stépán "Contact patch memory of tyres leading to lateral vibrations of four-wheeled vehicles", Philosophical Transactions of the Royal Society A, Mathematical Physical and Engineering Sciences, Vol. 371, No. 1993, Paper 20120427, p. 12., 2013

[3]. J. Łuczko, P. Cupiał and U. Ferdek, "Regular and Chaotic Vibrations of a Vibration-isolated Hand Grinder, " Journal of Theoretical and Applied Mechanics, Vol. 45 No. 1, pp. 61-72., 2007

[4]. J. Marzbanrad and A. Keshavarzi, "Chaotic Vibrations of a Nonlinear air Suspension System under Consecutive Half Sine Speed Bump," Indian Journal of Science \& Technology Vol.8 No.3, pp. 72-84, 2015

[5]. K.S.E. Hung, T.T. Chuan and A.L. Ann, "Reducing Vibration in Armoured Tracked Vehicles," DSTA Horizons, pp. 65-77., 2012

[6]. P. A. Borse and P.S. Desale, "Effect of Motor Vehicle Structural Vibration on Human Body - Review)," International Advanced Research Journal in Science, Engineering and Technology, Vol. 4 No. 7, pp. 145-149, 2017

[7]. R. Kuti: Rescue vehicles, rescue equipment (in Hungarian), University textbook, Zrínyi Miklós Nemzetvédelmi Egyetem, Budapest, pp. 45, 2007

[8]. R. Burdzik, L. Konieczny, "Vibration issues in passenger car," Transport Problems Vol. 9 No. 3, pp. 83-90, 2014

[9]. H. Nahvi, M. H. Fouladi, M. J. M. Nor, "Evaluation of Whole-Body Vibration and Ride Comfort in a Passenger Car", International Journal of Acoustics and Vibrations Vol. 14 No. 3., pp. 143-149, pp. 2009

[10]. M. Rikaz1 , A. Abeysinghe, M. Perera, "Review on vibration quality improvement of a passenger seat", Vibroengineering PROCEDIA. Vol. 22., pp. 106-111, 2019

[11]. L. Zhao, C. Zhou, Y. Yu, F. Yang, "A method to evaluate stiffness and damping parameters of cabin suspension system for heavy truck", Advances in Mechanical Engineering 8(7), pp. 1-9, 2016

[12]. W.J. Evers, I. Besselin, A. Teerhuis, T. Oomen, H. Nijmeijer, "Experimental validation of a quarter truck model using asynchronous measurements with low signal-to-noise ratios", 10th AVEC conference, Loughborough, UK. 22-26. August, 2010

[13]. O. Stan, D. Iozsa, R. Oprea: "Study concerning the influence of the engine mounting system on the vibration transmissibility to the truck cab", Recent Advances in Applied Mathematics, Modelling and Simulation, pp. 225-228, 2014

[14]. F. Hajdu and R. Kuti, "Examination of chaotic vibrations during operation of a fire truck", in Proceedings of MAC 2018 in Prague, pp. 163-170., 2018

[15]. J. Fakhraei, H:M. Khanlo, M. Ghayour, Chaotic behaviors of a ground vehicle oscillating system with passengers". Scientia Iranica, Vol. 24 No.3, pp. 1051-1068, 2017

[16]. Horváth P., "Basics of Mechatronics II (in Hungarian), ” Széchenyi István University, Győr, Hungary, 2006

[17]. H. Yarmohamadi, "Advances in Heavy Vehicle Dynamics with Focus on Engine Mounts and Individual Front Suspension", Phd thesis, Chalmers University of Technology, Göteborg, Sweden, supervisor: Viktor Berbyuk, 2012

[18]. Y. Cui, T.R. Kurfess, M. Messman, "Testing and Modeling of Nonlinear Properties of Shock Absorbers for Vehicle Dynamics Studies", Proceedings of the World Congress on Engineering and Computer Science 2010 Vol II WCECS 2010, October 20-22, 2010, San Francisco, USA, pp. 949-954

[19]. L. Jiao, Vehicle model for tyre-ground contact force evaluation, " Master thesis, KTH Royal Institute of Technology, 2013

[20]. D. Sekulić, V. Dedović, "The Effect of Stiffness and Damping of the Suspension System Elements on the Optimisation of the Vibrational Behaviour of a Bus" International Journal for Traffic and Transport Engineering (IJTTE). Vol. 1. No. 4. pp. 231-244, 2011

[21]. W.J. Evers, I. Besselin, A. Teerhuis, T. Oomen, H. Nijmeijer, "Experimental validation of a quarter truck model using asynchronous measurements with low signal-to-noise ratios", 10th AVEC conference, Loughborough, UK. 22-26. August, 2010

[22]. J. Konieczny, J. Kowal, J. Pluta, A. Podsiadlo. "Laboratory research of the controllable hydraulic damper". Engineering Transactions, Vol. 54 No.3, pp. 203-221., 2006

[23]. R.S. Barbosa, "Vehicle dynamic response due to pavement roughness" Journal of the Brazilian Society of Mechanical Sciences and Engineering, Vol. 33 No.3, 2011

[24]. X-engineer.org, "Road profile mathematical modeling for wheel vertical dynamics simulation", https://x-engineer.org/automotiveengineering/chassis/vertical-dynamics/road-profile-mathematical-modeling-for-wheel-vertical-dynamics-simulation/

[25]. K.L. Vasundhara, "Computer Interface in Euler and Fourth-order Runge - Kutta Method," International Advanced Research Journal in Science, Engineering and Technology, Vol 4. No. 10, pp. 127-132., 2017

[26]. Encyclopedia of Occupational Health and Safety, http://www.ilocis.org/en/default.html 